

\section{PRINCIPLE OF CLINCHING}

Clinching as most used method of mechanical joining is a metalworking process which can connect steel sheets effectively without any splashes, flashes or harmful light. The principle of this technique consists in pressing the bonded sheets into a specially shaped die (Fig. 1). With increasing pressure, the joined materials are forced to flow into the sides of the specially shaped die (Fig. 2). Two or more metal sheets should be joined (made of the same or different materials and up to a total joint thickness of about 5-6 mm) regardless of surface condition and without any edge preparation [9]. After the joint has been made, there is no need for repainting the sheets or performing stress relieving treatments [10-11].

In recent years, it is said that this method of materials joining will largely replace spot welding in car body production. In comparison with resistance spot welding, the clinching has the following advantages:

$>$ from 30 to $60 \%$ of cost savings compared to resistance spot welding,

$>$ simple, non-destructive quality control of the joint is possible,

$>$ the material is reinforced at the joint place; no surface cracks occur,

$>$ the clinched joint reaches about $50 \%$ of the static strength in comparison with resistance spot weld strength,

$>$ higher lifetime of active tool parts $(250,000$ to 300,000 joints) in comparison with resistance spot welding electrode tips (1000 to 5000 welds).
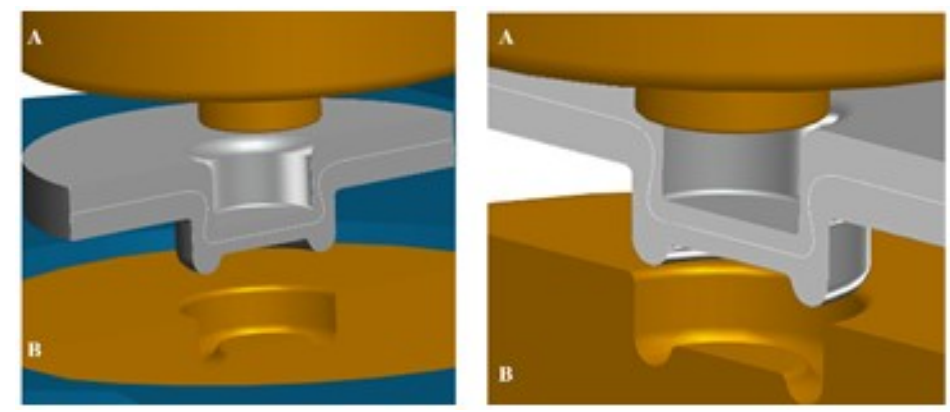

Fig. 1. Active parts of clinching tool: a) punch and b) die
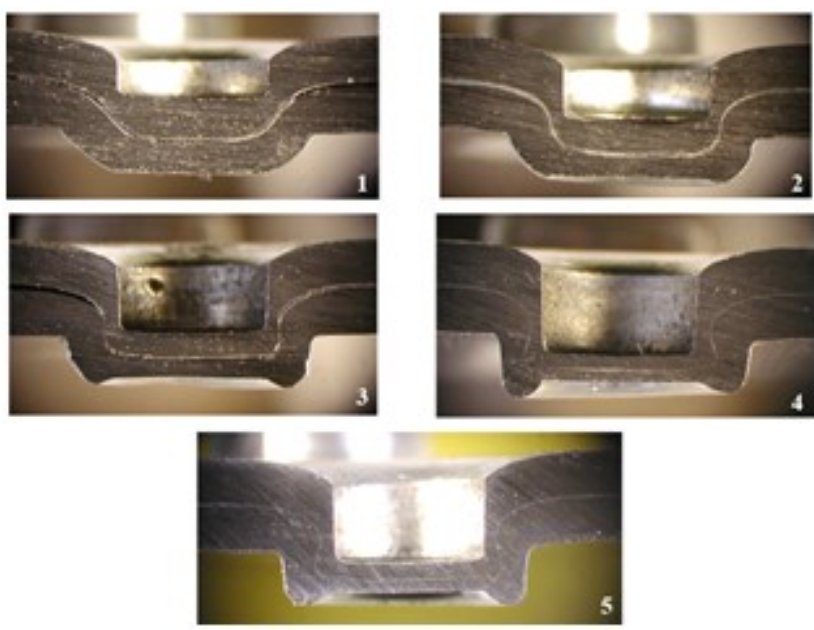

Fig. 2. Phases of clinched joint formation

\section{METHODICS AND EXPERIMENTS}

The hot-dip galvanized steel sheets of drawing quality DC01, DC04 and DX53D with various thickens were used for the experiments. The basic mechanical properties and chemical composition of these materials are shown in Tab. I and II.

Following samples for the experiments were created by combining these types of steel sheets:

- Sample I: DC01 (thickness $0.80 \mathrm{~mm}$ ) and DC01 (thickness $0.62 \mathrm{~mm}$ )

- Sample II: DC04 (thickness $1.00 \mathrm{~mm}$ ) and DC01 (thickness $0.62 \mathrm{~mm}$ )

- Sample III: DC01 (thickness $0.90 \mathrm{~mm}$ ) and DC01 (thickness $0.62 \mathrm{~mm}$ )

- Sample IV: DX53D (thickness $0.98 \mathrm{~mm}$ ) and DC01 (thickness $0.62 \mathrm{~mm}$ )

Three types of samples were produced: single-pressure samples, where thicker of the joined sheets were situated on the die side, samples with one pressure joint where the thinner of the joined sheets were on the die side and samples with double clinched joints. The samples with dimensions of $40 \times 90 \mathrm{~mm}$ and lapping of $30 \mathrm{~mm}$ were prepared for the experiments. For each sheets combination, 10 samples were prepared. The surfaces of joined steel sheets were not cleaned before clinching process.

The load-bearing capacity of the clinched joint was measured by static tensile test on the TIRAtest 2300 metal strength test machine of VEB TIW Rauenstein at a load speed of $8 \mathrm{~mm} / \mathrm{min}$, according to STN 051122 standard. 
TABLE I. BASIC MECHANICAL PROPERTIES OF JOINED MATERIALS

\begin{tabular}{|c|c|c|c|}
\hline $\begin{array}{c}\text { Material } \\
\text { (thickness) }\end{array}$ & $\begin{array}{c}\mathbf{R}_{\mathrm{e}} \\
{[\mathrm{MPa}]}\end{array}$ & $\begin{array}{c}\mathbf{R}_{\mathrm{m}} \\
{[\mathrm{MPa}]}\end{array}$ & $\begin{array}{c}\mathbf{A}_{80} \\
{[\%]}\end{array}$ \\
\hline $\begin{array}{c}\text { DC01 (0.62 } \\
\mathbf{m m})\end{array}$ & 153 & 270 & 46 \\
\hline $\begin{array}{c}\text { DC01 (0.80 } \\
\mathbf{m m}\end{array}$ & 167 & 281 & 44 \\
\hline $\begin{array}{c}\text { DC01 (0.90 } \\
\mathbf{m m})\end{array}$ & 175 & 285 & 42 \\
\hline $\begin{array}{c}\text { DC04 (1.0) } \\
\text { DX53D (0.98 } \\
\mathbf{m m}\end{array}$ & 239 & 341 & 36 \\
\hline
\end{tabular}

TABLE II. CHEMICAL COMPOSITION OF JOINED MATERIALS IN WT [\%]

\begin{tabular}{|c|c|c|c|c|c|}
\hline $\begin{array}{c}\text { Material } \\
\text { (thickness) }\end{array}$ & C & Mn & P & S & Al \\
\hline $\begin{array}{c}\text { DC01 } \\
\mathbf{( 0 . 6 2} \mathbf{~ m m})\end{array}$ & 0.05 & 0.27 & 0.013 & 0.014 & 0.039 \\
\hline $\begin{array}{c}\text { DC01 } \\
\mathbf{( 0 . 8 0 ~} \mathbf{~ m m})\end{array}$ & 0.04 & 0.162 & 0.008 & 0.0065 & 0.043 \\
\hline $\begin{array}{c}\text { DC01 } \\
\mathbf{( 0 . 9 0 ~} \mathbf{~ m m})\end{array}$ & 0.04 & 0.18 & 0.008 & 0.006 & 0.043 \\
\hline $\begin{array}{c}\mathbf{D C 0 4} \\
\mathbf{( 1 . 0 )}\end{array}$ & 0.083 & 0.332 & 0.009 & 0.0126 & 0.043 \\
\hline $\begin{array}{c}\mathbf{D X 5 3 D} \\
\mathbf{( 0 . 9 8} \mathbf{~ m m})\end{array}$ & 0.07 & 1.54 & 0.01 & 0.0032 & 0.052 \\
\hline
\end{tabular}

\section{RESULTS AND DISCUSSION}

The average values of the load-bearing capacity of the clinched joints are shown in Fig. 3. The samples with double clinched joints were formed only with a thinner sheet on the die side.

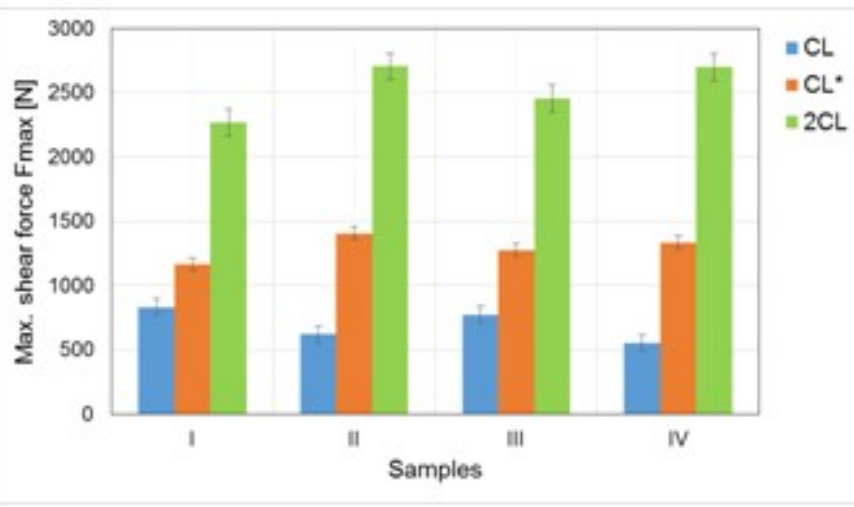

Average values of load-bearing capacity of clinched joints (*thinner sheet on the die side)

The highest values of load-bearing capacity were achieved with double clinched joints, followed by the samples with a single clinched joint when the thin sheet was oriented on the die side and the lowest loadbearing capacity was achieved with single clinched joints where the thinner sheet was on the punch side.

As can be seen in Fig. 4, the failure of the clinched joints depends on the orientation of the steel sheets relative to the punch and die. A deformed part of the top steel sheet along with a crack in the clinched joint is visible on the sample along the circumference of the joint - Fig. 4a. This part was torn from the lower, thinner plate. Figure $4 \mathrm{~b}$ shows the sample breakage occurred by rupturing the thinner bottom in the critical area of the joint, i.e. in the place with the largest thinning. The critical area of the joint is shown in Fig. 5. A typical example of a double clinched joint failure is shown in Fig. 6.
Upper

Sheet

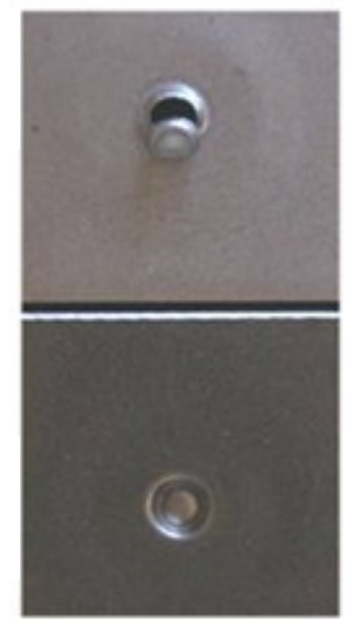

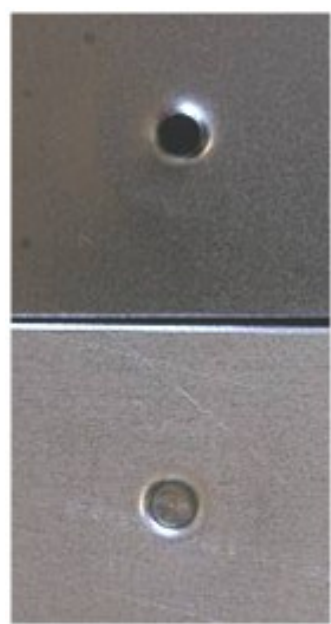

Upper Sheet

Lower Sheet a)

Lower

Sheet b)
Fig 4. Sample IV after tensile test: a) sheet of $0.62 \mathrm{~mm}$ on the die side, b) sheet of $0.98 \mathrm{~mm}$ on the die side 


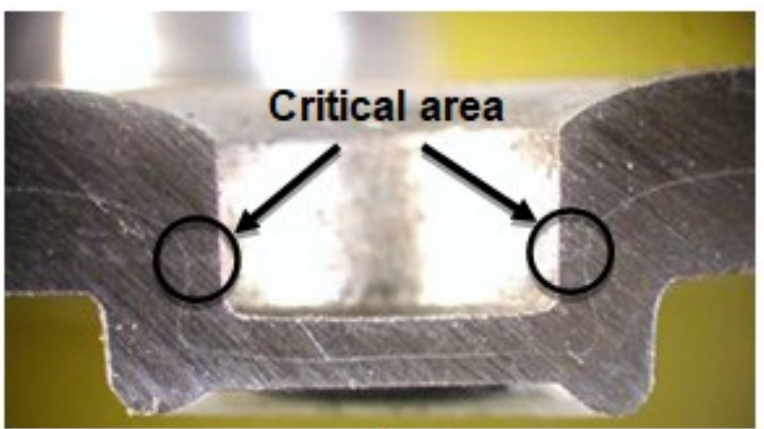

a)

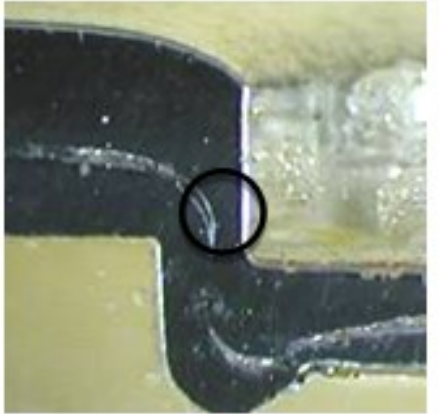

b)

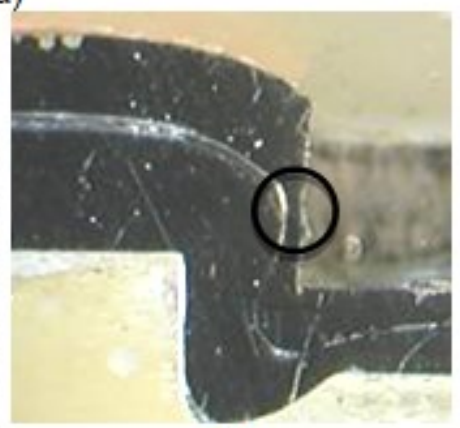

c)
Fig 5. a) Critical area in the clinched joint, b) thinner sheet on the die side, c) thinner sheet on the punch side

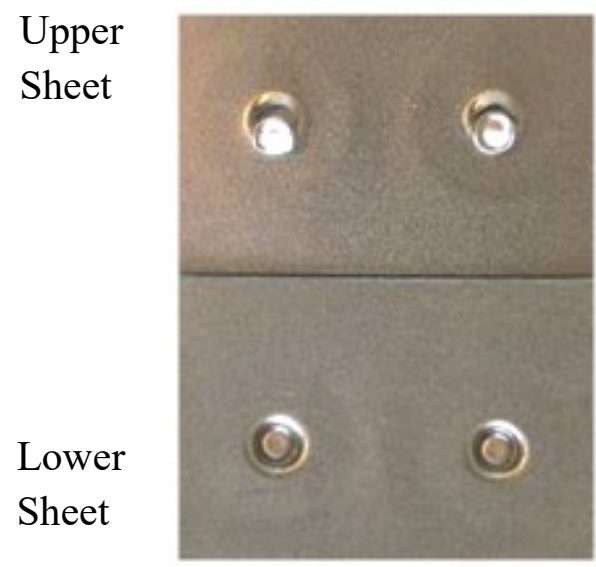

Fig 6. Sample III with double clinched joints after tensile test - thinner sheet of $0.62 \mathrm{~mm}$ on the die side

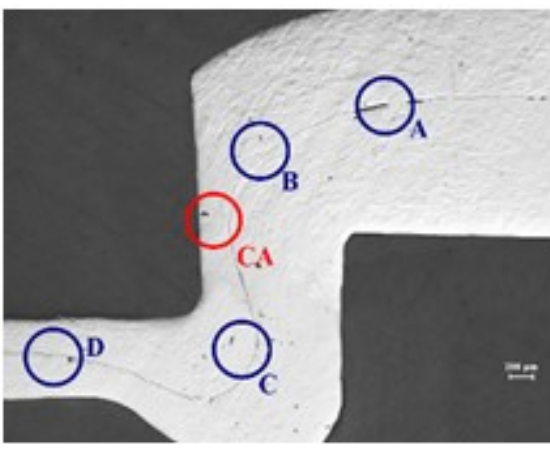

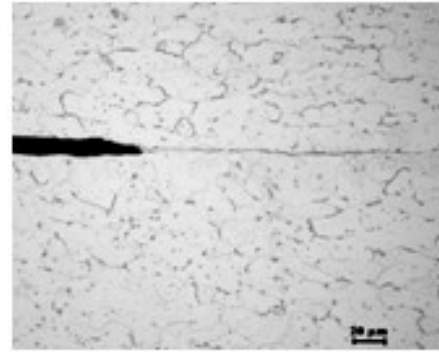

$\mathbf{A}$

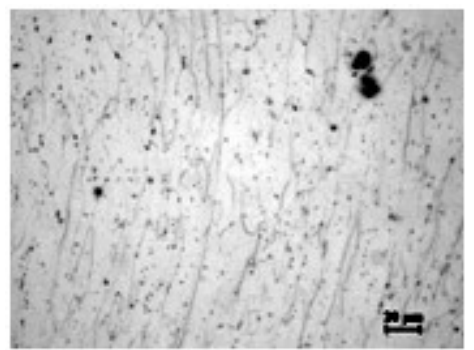

$\mathrm{C}$

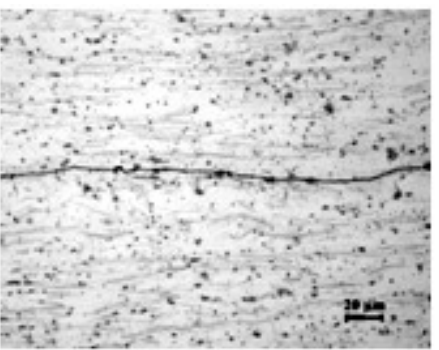

$\mathrm{D}$

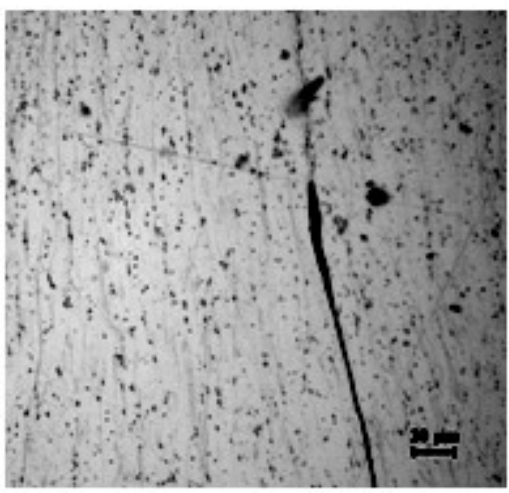

CA

Fig 7. The cross section of sample I (CA - critical area of the clinched joint

The average percent increase in load-bearing capacity of one joint in samples I when exchanging steel sheets relative to the punch and dies was $40.2 \%$, in samples II was $129.4 \%$, in samples III was $66 \%$ and in samples IV was $149.3 \%$. The increase in load-bearing capacity of double clinched joints compared to the one clinched joint (joint with a thinner sheet on the die side) was nearly $100 \%$ for all observed samples. 
The measured and the computed values show that the higher values of the load-bearing capacity of one clinched joint with the thinner sheet on the die side reached the samples II and IV, where the difference in the joined thicknesses of the materials was most significant.

Figure 7 shows a cross section of the part of pressure joint of the sample I (DC01, thickness of $0.8 \mathrm{~mm}+$ DC01, thickness of $0.62 \mathrm{~mm}$ ). In the place A, the structures of the two joined materials are visible without grain deformation caused by joining process. In the place $\mathrm{B}$, where the clinched joint starts to be created, the deformed grains of the joined materials are visible, with greater deformation on the top sheet. In the place $\mathrm{C}$, the deformation of the grains of both materials is almost the same. In the bottom of the clinched joint in the place $\mathrm{D}$, a considerable deformation of the grains of both materials was observed. There is more than $50 \%$ of the thinning in both joined steel sheets. At the bottom of the clinched joint and in the critical area of the clinched joint, the largest amount of thinning of the joined materials occurred.

\section{Conclusion}

The mechanical clinching is a relatively new method of material joining. Its usage in the automotive industry is increasing as an alternative to resistance spot welding or in cases where conventional joining method cannot be used. Research into properties of clinched joints in the automotive industry is mainly focused on their impact on the load-bearing capacity of the resulting parts. Since the 1990s, the tailored blanks consisting of materials of different qualities and thicknesses are investigated by the ULSAB (UltraLight Steel Auto Body) project. This also closely relates to the need for research into the joining of materials of different thicknesses and qualities using various joining methods.

On the basis of the conducted experiment, the following conclusions can be formed:

$>$ the results of the tensile test as well as the metallographic observations confirmed the mechanical clinching as a suitable method for joining the tested combination of materials,

$>$ the highest values of load-bearing capacity were achieved with double clinched joints,

$>$ load-bearing capacity of the clinched joints varies significantly depending on the orientation of the sheets in the testing sample, when clinching materials of different thickness, it is advantageous to orient the joined materials so that the thinner sheet is on the die side and the thicker sheet on the punch side.

\section{Acknowledgment}

Author is grateful for the support of experimental works by project VEGA 1/0441/17 - Application of high-strength materials for outer car body parts.

\section{References}

1) Y. Abe, T. Kato, K. M and S. Nishino, "Mechanical clinching of ultra-high strength steel sheets and strength of joints," J. Mater. Process. Tech., vol. 214, pp. 2112-2118, 2014.

2) N. Nong, O. Keju, Z. Yu, Q. Zhiyuan, T. Changcheng and L. Feipen, "Research on press joining technology for automotive metallic sheets," J. Mater. Process. Tech., vol. 137, pp. 159-163, 2003.

3) L. Kaščák, E. Spišák and J. Majerníková, "Joining three car body steel sheets by clinching method," Open Eng., vol. 6, pp. 566-573, 2016.

4) C.J. Lee, J.Y. Kim, S.K. Lee, D.C. Ko and B.M. Kim, "Parametric study on mechanical clinching process for joining aluminum alloy and highstrength steel sheets," J. Mech. Sci. Technol., vol. 24, pp. 123-126, 2010.

5) T. Jiang, Z.X. Liu, and P.C. Wang, "Effect of aluminum pre-straining on strength of clinched galvanized SAE1004 steel-to-AA6111-T4 aluminum," J. Mater. Process. Tech., vol. 215, pp. 193-204, 2015.

6) J. Mucha and W. Witkowski, "The clinching joints strength analysis in the aspects of changes in the forming technology and load conditions," Thin. Wall. Struct., vol. 82, pp. 55-66, 2014.

7) L. Kaščák, E. Spišák, R. Kubík and J. Majerníková, "Clinching hot-dip galvanized steel combined with aluminium alloy," Acta Metall. Slovaca, vol. 21, pp. 321-329, 2015.

8) L. Kaščák and E. Spišák, "Possibilities of using the technology of mechanical clinching of thin steel sheets of different thicknesses and qualities," Acta Mech. Slovaca, vol. 2-B, pp. 175-180, 2004.

9) M. Israel, R. Mauermann and J. Schellnock, "Thick sheet clinching - joining up to $20 \mathrm{~mm}$ total thickness," ASOE, vol. 2, pp. 1-10, 2013. 
10) T. Pinger and E.M. Rückriem, "Investigation on the corrosion and mechanical behavior of thin film batch galvanized thick plate components in clinch joints," Int. J. Adv. Manuf. Technol., vol. 86, pp. 29-36, 2016.

11) T.A. Barnes and I.R. Pashby, "Joining techniques for aluminium spaceframes used in automobiles: part II adhesive bonding and mechanical fasteners," J. Mater. Process. Tech., vol. 99, pp. 72-79, 2000. 